\title{
Inverse temporal contributions of the dorsal hippocampus and medial prefrontal cortex to the expression of long-term fear memories
}

\author{
Jennifer J. Quinn, ${ }^{1}$ Quang D. Ma, ${ }^{1}$ Matthew R. Tinsley, ${ }^{1}$ Christof Koch, ${ }^{2}$ \\ and Michael S. Fanselow ${ }^{1,3}$ \\ ${ }^{1}$ Department of Psychology and Brain Research Institute, UCLA, Los Angeles, California 90095-1563, USA; ${ }^{2}$ Division of Biology, \\ California Institute of Technology, Pasadena, California 91125, USA
}

\begin{abstract}
Retrograde amnesia following disruptions of hippocampal function is often temporally graded, with recent memories being more impaired. Evidence supports the existence of one or more neocortical long-term memory storage/retrieval site(s). Neurotoxic lesions of the medial prefrontal cortex (mPFC) or the dorsal hippocampus (DH) were made 1 day or 200 days following trace fear conditioning. Recently encoded trace fear memories were most disrupted by DH lesions, while remotely encoded trace and contextual memories were most disrupted by mPFC lesions. These data strongly support the consolidation theory of hippocampus function and implicate the mPFC as a site of long-term memory storage/retrieval.
\end{abstract}

The consolidation of memories into their long-term, stabilized form is a topic of considerable theoretical and empirical scientific inquiry (McGaugh 2000; Squire et al. 2004; Frankland and Bontempi 2005; Wiltgen et al. 2005a). Independent brain circuits underlie different forms of memory, and, within a particular memory domain, the contribution of a specific region may depend upon the age of that memory (Ribot 1882; Squire 1992; Knowlton and Fanselow 1998; Frankland and Bontempi 2005).

Consolidation theory suggests that memories are gradually reorganized such that the brain regions responsible for the storage/retrieval of a memory are changed (Marr 1971; McClelland et al. 1995; Squire and Alvarez 1995). Early evidence for this came from the characteristic pattern of temporally graded retrograde amnesia for declarative memories in human patients who had suffered insult to the medial temporal lobe (e.g., Scoville and Milner 1957). Similar patterns have been observed in animals using more circumscribed manipulations of the hippocampus across a variety of procedures, including object discrimination (Zola-Morgan and Squire 1990), contextual fear conditioning (Kim and Fanselow 1992; Anagnostaras et al. 1999), trace eyeblink conditioning (Kim et al. 1995; Takehara et al. 2002), and social transmission of food preference (Clark et al. 2002).

In recent years, a shift has occurred toward identifying extrahippocampal regions that support long-term memories, and the medial prefrontal cortex (mPFC) has been implicated. The hippocampus and mPFC are functionally interrelated through correlated activity patterns that may be important for memory consolidation (Jay and Witter 1991; Siapas and Wilson 1998; Sutherland and McNaughton 2000; Siapas et al. 2005). Bontempi et al. (1999) showed that metabolic activity in the mPFC increases with longer retention intervals and Frankland et al. (2004) found temporal gradients for Zif-268 and Fos activation in the mPFC following contextual fear conditioning. Lesions of mPFC disrupt trace eyeblink conditioning (Simon et al. 2005), and the magnitude of the disruption is positively correlated with the trainingto-lesion interval (Takehara et al. 2003).

\footnotetext{
${ }^{3}$ Corresponding author.
}

E-mail mfanselow@gmail.com; fax (310) 206-5895.

Article is online at http://www.learnmem.org/cgi/doi/10.1101//m.813608.
We assessed the role of the dorsal hippocampus (DH) and $\mathrm{mPFC}$ in trace and contextual fear memories. DH involvement in both trace and contextual fear conditioning has been previously demonstrated (e.g., McEchron et al. 1998; Quinn et al. 2002, 2005; Chowdhury et al. 2005). While a temporally graded retrograde amnesia for contextual fear conditioning is well established (e.g., Kim and Fanselow 1992; Anagnostaras et al. 1999), a similar assessment of trace fear conditioning has not yet been made. This experiment allows us to assess temporal gradients for two hippocampus-dependent memories within the same animal and determine whether the $\mathrm{mPFC}$ serves as a permanent storage/retrieval site for these memories.

\section{Results}

Figure 1 shows reconstructions of the minimal and maximal extent of mPFC and DH lesions for animals included in all analyses. Nine animals were excluded from all analyses due to unilateral lesion extent.

$\mathrm{mPFC}$ and $\mathrm{DH}$ inversely contribute to the expression of recent and remote fear memories

As shown in Figure 2, there is an interaction between the age of fear memories (recent vs. remote) and the surgery condition. ANOVA revealed a reliable interaction between lesion location and training-to-surgery interval for trace tone $\left(F_{(2,78)}=6.65\right.$, $P<0.01)$ and contextual $\left(F_{(2,78)}=3.91, P<0.05\right)$ fear memories.

mPFC and DH differentially contribute to the consolidation of trace tone fear memories Freezing data from the tone test are displayed at the top in Figure $3 \mathrm{~A}-\mathrm{D}$. The mean freezing $( \pm$ SEM) during the initial 3-min baseline period in the novel tone test context is presented for unpaired controls and for trace-conditioned sham, $\mathrm{mPFC}$, and $\mathrm{DH}$ animals at each of the surgery times: $1 \mathrm{~d}$ post-training (panel A) and $200 \mathrm{~d}$ post-training (panel B). The mean freezing $( \pm$ SEM) across the three test tones is similarly presented for each group in panels $\mathrm{C}$ and $\mathrm{D}$. 


\section{Medial Prefrontal Cortex (mPFC) Lesions}
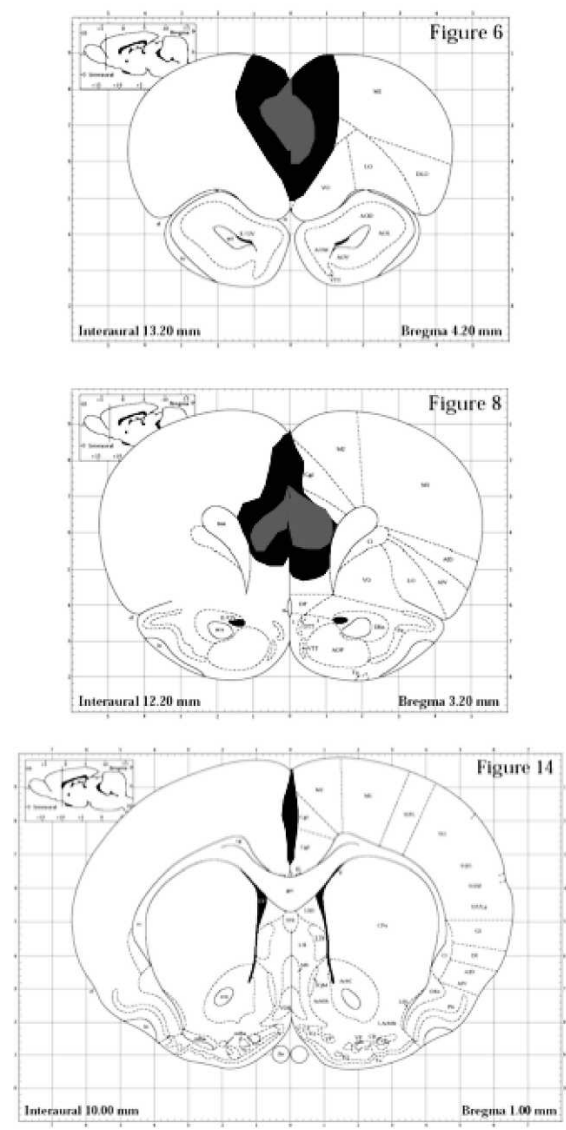

\section{Dorsal Hippocampus (DH) Lesions}
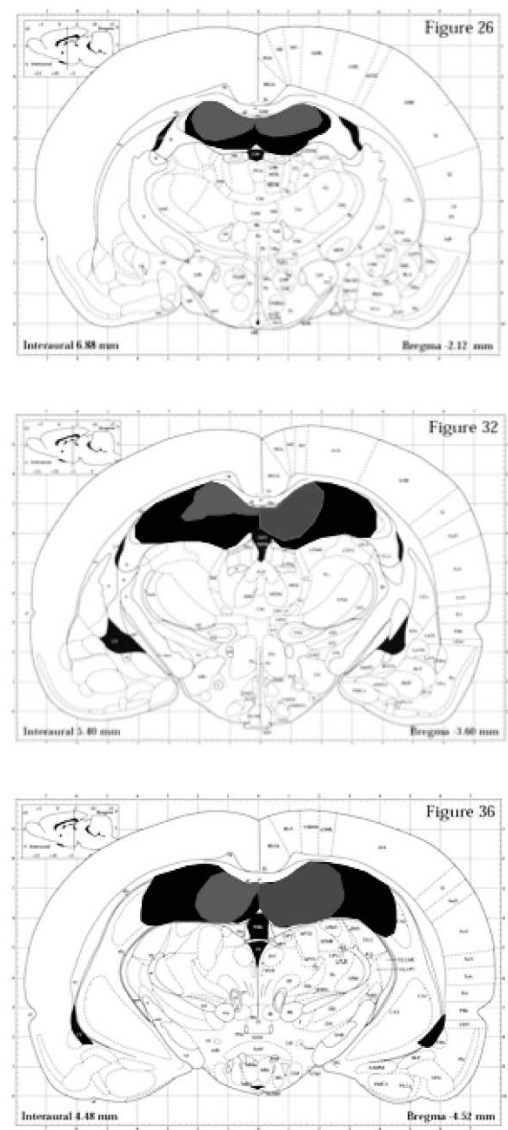

Figure 1. Reconstructions of the minimal (gray) and maximal (black) extent of mPFC and DH lesions for animals included in all analyses. The mPFC lesions are centered in the prelimbic/infralimbic region (average damage $62 \%$ of total) and generally spared the anterior cingulate cortex (average damage $8 \%$ of total). The $\mathrm{DH}$ lesions (average damage $58 \%$ of total) generally encompass damage to dentate, CA1 and CA3 rostrally, with more sparing of CA3 caudally. No damage to intermediate or ventral hippocampus is observed. Atlas figures are reproduced with permission from Elsevier @ 1997, Paxinos and Watson (1997).

\section{One day post-training surgeries}

In animals given surgery $1 \mathrm{~d}$ following training and tested $11-12 \mathrm{~d}$ later, baseline freezing in the novel tone test context (Fig. 3A) was low in all groups $(<15 \%)$, and there were no differences between groups $(P s>0.05)$. As shown in Figure 3C, sham trace animals froze more to the tone than unpaired controls $\left(t_{(28)}=4.77\right.$, $P<0.0001)$, suggesting that freezing to the trace tone was the result of associative conditioning. Trace tone fear conditioning differed as a result of surgery $\left(F_{(2,38)}=4.51, P<0.05\right)$, and pairwise comparisons using Fisher's PLSD $(P<0.05)$ revealed that DH lesion rats froze reliably less than sham controls. However, mPFC lesions made at this time point had no effect on the level of trace tone fear.

\section{Two-hundred days post-training surgeries}

In animals given surgery $200 \mathrm{~d}$ following training and tested 11-12 d later, baseline freezing in the novel tone test context (Fig. 3B) was higher than that seen in the $1 \mathrm{~d}$ post-training surgery groups $\left(F_{(1103)}=22.21, P<0.0001\right)$, and this is consistent with recent findings (e.g., Wiltgen and Silva 2007). Sham trace and unpaired $200 \mathrm{~d}$ surgery rats did not differ in novel context freezing $(F<1)$. However, traceconditioned rats differed as a function of surgery $\left(F_{(2,40)}=4.87, P<0.05\right)$ and pairwise comparison's using Fisher's PLSD $(P<0.05)$ revealed that traceconditioned rats with DH or mPFC lesions showed reliably less novel context freezing than sham controls. As shown in Figure 3D, sham trace-conditioned rats froze more to the tone than unpaired controls $\left(t_{(33)}=2.85, P<0.01\right)$, suggesting that freezing to the trace tone was associative. Rats that received surgery $200 \mathrm{~d}$ following trace fear conditioning differed in tone fear levels depending on surgery condition $\left(F_{(2,40)}=5.85, P<0.01\right)$. Completely opposite to the pattern observed in the $1 \mathrm{~d}$ post-training lesion conditions, mPFC lesion animals froze reliably less than sham controls $(P<0.01)$, but there was no effect of DH lesion at this time point (Fig. 3D).

\section{mPFC and DH differentially contribute to the consolidation of contextual fear memories}

Mean freezing $( \pm$ SEM) during the context test is displayed at the bottom in Figure 3, E and F. Analyses of context freezing were limited to the first $256 \mathrm{sec}$ of the test since substantial extinction occurred during the latter half of the test period.

\section{One day post-training surgeries}

Unpaired controls and sham trace conditioned animals did not differ in their levels of context freezing $(F<1)$. Animals that received surgery 1 day following trace fear conditioning differed in their levels of contextual fear as a result of surgery $\left(F_{(2,38)}=5.56, P<0.01\right)$. Subsequent comparisons using Fisher's PLSD showed that both mPFC $(P<0.05)$ and DH $(P<0.01)$ lesion groups froze reliably less than sham controls (Fig. $3 \mathrm{E}$ ).

\section{Two-hundred days post-training surgeries}

Sham trace-conditioned rats froze more than unpaired controls during the context test $\left(t_{(33)}=2.88, P<0.01\right)$. Rats that received surgery $200 \mathrm{~d}$ following trace fear conditioning differed in contextual fear levels depending on surgery condition $\left(F_{(2,40)}=18.27, P<0.0001\right)$. Subsequent comparisons using Fisher's PLSD showed that both mPFC $(P<0.0001)$ and DH $(P<0.01)$ animals froze less than sham controls, with the magnitude of the mPFC lesion deficit being larger $(P<0.01)$ (Fig. 3F).

Tone freezing in unpaired controls differs with time As shown in Figure 3, C and D, the level of tone freezing in the unpaired animals varied as a function of the training-to-surgery interval where the $200 \mathrm{~d}$ unpaired animals froze more to the tone compared to the $1 \mathrm{~d}$ unpaired animals $\left(t_{(25)}=3.86, P<0.001\right)$. However, as shown in Figure $3, \mathrm{~A}$ and $\mathrm{B}$, these rats also differed in 


\section{Temporal Interaction}

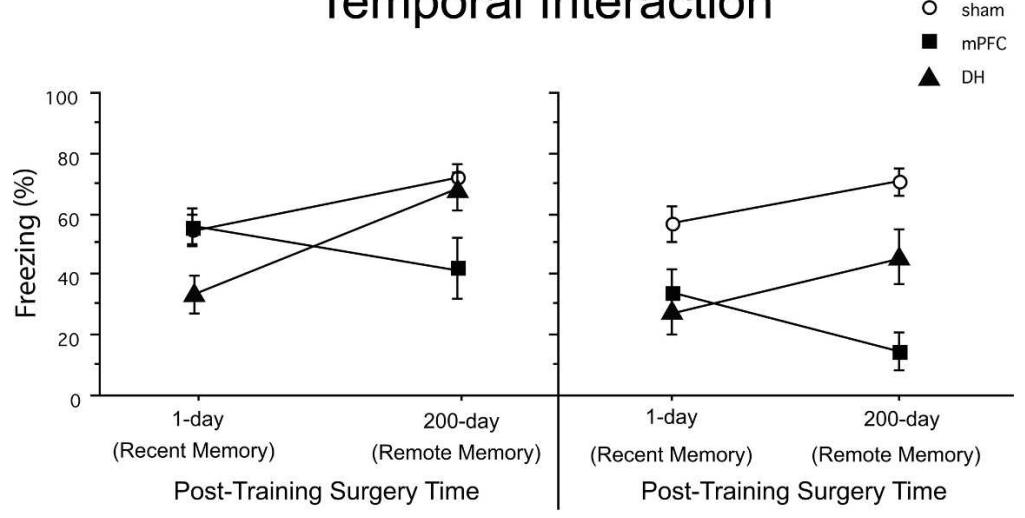

Figure 2. Temporal interactions among trace-conditioned sham, DH, and mPFC lesion animals as a function of the training-to-lesion interval are shown for both trace tone and context fear. DH lesions made $1 \mathrm{~d}$ following training produce a greater attenuation in both trace and contextual fear, relative to $\mathrm{DH}$ lesions made $200 \mathrm{~d}$ following training. The opposite pattern is observed in mPFC lesion animals.

novel context freezing during the baseline period of the tone test $\left(t_{(25)}=2.52, P<0.05\right)$, and this could explain differences observed during the tone. As shown in Figure 3, E and F, these rats showed comparable levels of contextual fear conditioning whether the surgery was done 1 or $200 \mathrm{~d}$ post-training $(F<1)$.

\section{Discussion}

These data are the first to show a temporally graded retrograde amnesia for trace fear conditioning following insult to the hippocampus. Further, they provide strong support for mPFC involvement in the long-term storage/retrieval of both trace and contextual fear conditioning. Most notably, the contributions made by the $\mathrm{mPFC}$ and $\mathrm{DH}$ are inversely related; recent trace fear memories are most disrupted by lesions of the $\mathrm{DH}$, whereas remote trace and contextual fear memories are most disrupted by mPFC lesions.

The mPFC involvement in trace and contextual fear conditioning following long retention intervals is consistent with recent observations (Takehara-Nishiuchi et al. 2005, 2006). Bontempi et al. (1999) showed that retention of a spatial discrimination is associated with elevated metabolic activity in the $\mathrm{DH}$ $5 \mathrm{~d}$ following acquisition, whereas activity in this region $25 \mathrm{~d}$ following acquisition is significantly attenuated; frontal cortical activity showed an opposite pattern. Takehara et al. (2003) observed a similar pattern using aspiration lesions of either the DH or mPFC following trace eyeblink conditioning. Lesions were made at various time points ranging from $1 \mathrm{~d}$ to $4 \mathrm{wk}$ following acquisition. The magnitude of the lesion deficits varied as a function of the training-to-lesion interval: $\mathrm{DH}$ lesion deficits were largest when made $1 \mathrm{~d}$ post-training, whereas the $\mathrm{mPFC}$ lesion deficits were largest when made 4 wk post-training. Finally, Frankland et al. (2004) observed an almost identical pattern using transient lidocaine inactivation of the anterior cingulate cortex (ACC) at various time points following contextual fear conditioning. While they observed no deficit in contextual fear expression 1 or $3 \mathrm{~d}$ following acquisition, inactivation of the ACC 18 or $36 \mathrm{~d}$ following training attenuated freezing to the conditioning context. Interestingly, lidocaine infusions directed at the prelimbic region of the mPFC had no effect on contextual fear expression despite the observed increases in Zif- 268 and Fos expression in this region. It is difficult to reconcile the discrepancy between the lidocaine results and the present lesion results. Our $\mathrm{mPFC}$ lesions produced very limited damage to the rostral ACC. More focused studies to explore these differences will be necessary. It is possible that the different conditioning procedures and/or different species used in the two experiments altered the relative involvement of the mPFC and ACC in the longterm storage/retrieval of the fear memories. Given the extensive interconnections between these frontal cortical regions (Jones et al. 2005), it is not surprising that both regions may make contributions.

The present results contrast with those recently reported by Blum et al. (2006) showing comparable trace tone fear conditioning deficits produced by mPFC muscimol inactivations given 2 or $30 \mathrm{~d}$ post-training. It is unclear why excitotoxic lesions and transient inactivations should have such differential effects, aside from differences between the manipulations themselves or the very different remote time points (30 versus 200 d). However, Blum et al. (2006) did not employ any controls to allow for assessment of nonassociative contributions to performance. Perhaps the infusion procedure increases anxiety, resulting in an increase in freezing during the tone test. We speculate that if the mPFC contributes to this nonassociative response, inactivation of this region would be expected to reduce freezing at both time points.

One difference between the present experiment and previous experiments examining temporally graded retrograde amnesia is the very long training-to-lesion interval used for the remote memories in the present experiment. While previous experiments generally examined "remote" memories using manipulations made $\sim 1$ mo following acquisition, our remote lesions were made almost 7 mo following acquisition. However, the temporal gradient for contextual fear conditioning appears to be much longer when employing neurotoxic lesions similar to those used in the present experiment (Maren et al. 1997; J. Quinn and M. Fanselow, unpubl.). In fact, even with the $200 \mathrm{~d}$ training-tolesion interval used here, neurotoxic lesions of the $\mathrm{DH}$ produced a reliable deficit in contextual, but not trace, fear conditioning. By contrast, Kim and Fanselow (1992) and Anagnostaras et al. (1999) found no effect of electrolytic lesions of the DH made $28-50 \mathrm{~d}$ following training. Another possibility is that conditioning to context during a trace fear conditioning procedure yields a flatter retrograde gradient than is observed following either context-alone or delay fear conditioning. Support for this possibility comes from data showing that context fear memory becomes more sensitive to manipulations of the hippocampus following trace (compared to delay) fear conditioning (Wiltgen et al. 2005b).

It remains unclear the extent to which the region involved in the initial storage and consolidation (e.g., DH) participates in the gradual recruitment of the permanent storage/retrieval region (e.g., mPFC). That is, do the two regions interact in some way that allows consolidation to occur? Perhaps the hippocampus is necessary to "teach" the mPFC over time? This idea is central to a number of contemporary theories of consolidation (e.g., McClelland et al. 1995; Buzsaki 1996). Alternatively, is it necessary for both regions to be functioning at the time of acquisition in order for consolidation to occur? While the present data are most consistent with the former, it remains possible that the $\mathrm{mPFC}$ does not store the memory at all but rather adopts the "indexing" functions of the hippocampus (Teyler and DiScenna 1986). Trace fear conditioning might aid in further exploring these questions due to the very clear temporal distinction between DH and mPFC contributions. 
A 1-day Post-Training Surgeries: A Baseline Freezing (Novel Context)

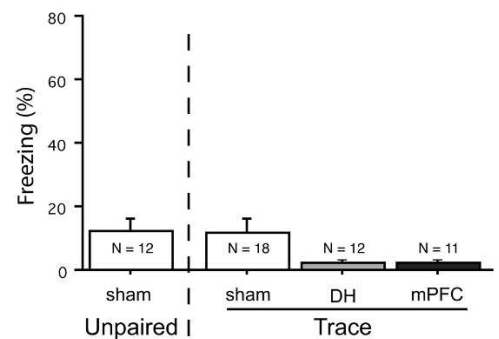

C 1-day Post-Training Surgeries:

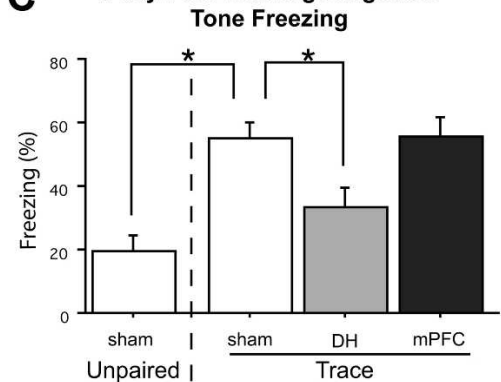

D 200-day Post-Training Surgeries:

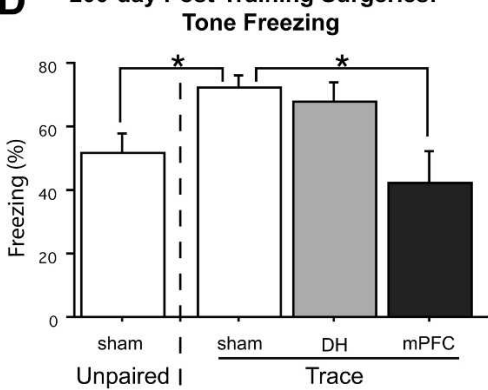

E 1-day Post-Training Surgeries:

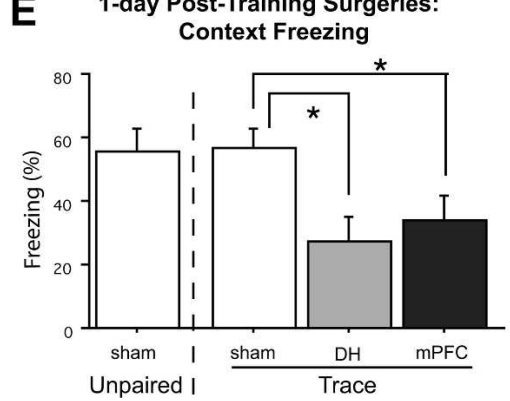

$\mathbf{F}$

F 200-day Post-Training Surgeries:

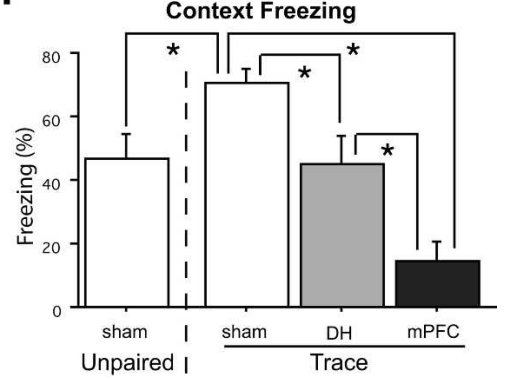

Figure 3. Mean ( \pm SEM) percentages of observations spent freezing during the first 192-sec baseline period in the novel tone test context $(A, B)$, the three test tones $(C, D)$, and the first $256 \mathrm{sec}$ of the context test $(E, F)$ are presented for unpaired controls and trace-conditioned sham, DH, and mPFC lesion animals at each of the surgery times: $1 \mathrm{~d}$ post-training and $200 \mathrm{~d}$ post-training. Novel context freezing is higher in $200 \mathrm{~d}$ surgery animals. Lesions of either DH or mPFC disrupt both trace tone and context fear conditioning, although the magnitude of the attenuation depends upon the training-tolesion interval.

\section{Materials and Methods}

\section{Subjects}

One hundred eleven experimentally naïve male Long-Evans adult rats (Harlan) were used in this experiment. They were individually housed on a 14:10 light/dark schedule with ad libitum access to food and water. Animals were handled 20 sec per day for 5 consecutive days prior to training and testing. All experimental procedures occurred during the light and in accordance with the UCLA IACUC.

\section{Behavioral apparatus}

Eight conditioning chambers $(28 \times 21 \times 21 \mathrm{~cm}$; Lafayette Instrument Co.) were used for conditioning and context testing. The front door, back wall, and ceiling were made of clear Plexiglas. The side walls were made of aluminum. Each grid floor was wired to a shock generator and scrambler (Med Associates, Inc.). A stainless steel pan coated with benzaldehyde $(2.5 \mu \mathrm{L}$ of benzaldehyde per $1 \mathrm{~mL}$ of absolute ethyl alcohol) was inserted under the grid floor to provide an odor. The chamber was cleaned with
$5 \% \mathrm{NaOH}$. A room fan provided background noise $(65 \mathrm{~dB})$, and the overhead room lights remained on.

Eight chambers located in a different experimental room were used for tone testing. They were similar to those used for training except that each chamber contained a white Plexiglas triangular insert. In addition, the floor was made of white Plexiglas. A 1\% glacial acetic acid solution was used for cleaning and scenting. Constant background white noise (65 $\mathrm{dB})$ was used, and room lighting was provided by a red light bulb $(30 \mathrm{~W})$.

\section{Surgery}

Animals were anesthetized with $55 \mathrm{mg} /$ $\mathrm{kg}$ sodium pentobarbital i.p., mounted into a stereotaxic system, and the skull was leveled. DH lesion coordinates (from bregma) included the following rostral sites (AP $-2.8 \mathrm{~mm}$; $\mathrm{ML} \pm 1.6 \mathrm{~mm}$; DV $-4.3 \mathrm{~mm}$ from skull) and caudal sites (AP $-4.3 \mathrm{~mm} ; \mathrm{ML} \pm 2.6 \mathrm{~mm}$; DV $-4.0 \mathrm{~mm}$ from skull). Medial PFC lesion coordinates (from bregma) included the following rostral sites (AP $+3.3 \mathrm{~mm}$; $\mathrm{ML} \pm 0.5 \mathrm{~mm}$; DV $-3.5 \mathrm{~mm}$ from dura) and caudal sites (AP +2.6 $\mathrm{mm} ; \mathrm{ML} \pm 0.5 \mathrm{~mm}$; DV $-3.5 \mathrm{~mm}$ from dura). The injector (28 gauge) was connected to an infusion pump (Harvard Apparatus). NMDA (20 $\mu \mathrm{g} / \mu \mathrm{L} ;$ Sigma) was dissolved in phosphate-buffered saline (PBS). For DH lesions, infusions took place across $4 \mathrm{~min}(0.1 \mu \mathrm{L} / \mathrm{min})$, and the injector was left in place for an additional $5 \mathrm{~min}$. For $\mathrm{mPFC}$, infusions took place across $2 \mathrm{~min}(0.1 \mu \mathrm{L} / \mathrm{min})$, and the injector was left in place for an additional $5 \mathrm{~min}$. Sham surgery was similar except that no injector was lowered and no drug infused.

\section{Procedure}

On day 1 , rats received 10 trials of either trace or unpaired fear conditioning within a single session. A trace conditioning trial consisted of a 16-sec tone (2 $\mathrm{kHz}, 72 \mathrm{~dB}$ ) followed by a 28-sec "stimulus-free" trace interval and then a 2 -sec footshock $(0.9 \mathrm{~mA})$. Unpaired conditioning consisted of 10 tone presentations followed by 10 footshock presentations, or vice versa. The inter-trial interval was $256 \mathrm{sec}$ (tone-onset to tone-onset) for trace conditioning, and the inter-stimulus interval was $128 \mathrm{sec}$ (stimulus onset to stimulus onset) for unpaired conditioning, thus producing equal training session lengths across all animals.

Twenty-four hours following conditioning, half of the animals underwent surgery. All other animals remained undisturbed in their homecages on this day. Two hundred days following training, the rest of the animals underwent surgery. Eleven days following surgery, animals received one context and one tone test session across two consecutive days in counterbalanced order. For the context test, they were placed into the training context (no tones or footshocks). For the tone test, they were placed into a novel context and received three presentations of the 16sec tone used during training, separated by $4 \mathrm{~min}$. Defensive freezing, defined as the absence of movement, except that necessitated by respiration (e.g., Fanselow 1980), was used as the dependent measure. A blind observer scored each rat every $8 \mathrm{sec}$ during the context test and every 2 sec for the duration of the 
tone test. Animals were anesthetized and perfused with $0.9 \%$ saline and $10 \%$ formaldehyde. The brain was stored in $10 \%$ formalin/30\% sucrose solution, cut into $50-\mu \mathrm{m}$ coronal sections, mounted, and stained using thionin. Images of whole sections at the rostral-caudal levels shown in Figure 1 were captured, and the area of the lesion was calculated using an image processing and analysis program (ImageJ, NIH). The percentage of tissue damaged in each section was calculated by dividing the area of lesioned tissue by the total area of that brain region.

\section{Acknowledgments}

We thank C.J. Han, David Anderson, Barbara Knowlton, Frank Krasne, and David Jentsch for thoughtful discussion. This work was supported by NSF grant no. IBN9723295 to M.S.F., NIMH grant no. 5F31MH066549 to J.J.Q., and by a Discovery grant from the Gordon and Betty Moore Foundation. J.J.Q. is currently in the Department of Psychiatry, Yale University. Q.D.M. is currently in the School of Medicine at Western University. M.R.T. is currently at Roche Pharmaceuticals.

\section{References}

Anagnostaras, S.G., Maren, S., and Fanselow, M.S. 1999. Temporally graded retrograde amnesia of contextual fear after hippocampal damage in rats: Within-subjects examination. J. Neurosci. 19: 1106-1114.

Blum, S., Hebert, A.E., and Dash, P.K. 2006. A role for the prefrontal cortex in recall of recent and remote memories. Neuroreport 17: 341-344.

Bontempi, B., Laurent-Demir, C., Destrade, C., and Jaffard, R. 1999. Time-dependent reorganization of brain circuitry underlying long-term memory storage. Nature 400: 671-675.

Buzsaki, G. 1996. The hippocampo-neocortical dialogue. Cereb. Cortex 6: 81-92.

Chowdhury, N., Quinn, J.J., and Fanselow, M.S. 2005. Dorsal hippocampus involvement in trace fear conditioning with long, but not short, trace intervals in mice. Behav. Neurosci. 119: 1396-1402.

Clark, R.E., Broadbent, N.J., Zola, S.M., and Squire, L.R. 2002. Anterograde amnesia and temporally graded retrograde amnesia for a nonspatial memory task after lesions of hippocampus and subiculum. J. Neurosci. 22: 4663-4669.

Fanselow, M.S. 1980. Conditional and unconditional components of post-shock freezing. Pavlovian J. Biol. Sci. 15: 177-182.

Frankland, P.W. and Bontempi, B. 2005. The organization of recent and remote memories. Nat. Rev. Neurosci. 6: 119-130.

Frankland, P.W., Bontempi, B., Talton, L.E., Kaczmarek, L., and Silva, A.J. 2004. The involvement of the anterior cingulate cortex in remote contextual fear memory. Science 304: 881-883.

Jay, T.M. and Witter, M.P. 1991. Distribution of hippocampal CA1 and subicular efferents in the prefrontal cortex of the rat studied by means of anterograde transport of Phaseolus vulgaris-leucoagglutinin. J. Comp. Neurol. 313: 574-586.

Jones, B.F., Groenewegen, H.J., and Witter, M.P. 2005. Intrinsic connections of the cingulate cortex in the rat suggest the existence of multiple functionally segregated networks. Neuroscience 133: 193-207.

Kim, J.J. and Fanselow, M.S. 1992. Modality-specific retrograde amnesia of fear. Science 256: 675-677.

Kim, J.J., Clark, R.E., and Thompson, R.F. 1995. Hippocampectomy impairs the memory of recently, but not remotely, acquired trace eyeblink conditioned responses. Behav. Neurosci. 109: 195-203.

Knowlton, B.J. and Fanselow, M.S. 1998. The hippocampus, consolidation and on-line memory. Curr. Opin. Neurobiol. 8: $293-296$.

Maren, S. and Aharonov, G., and Fanselow, M.S. 1997. Neurotoxic lesions of the dorsal hippocampus and Pavlovian fear conditioning in rats. Behav. Brain Res. 88: 261-274.

Marr, D. 1971. Simple memory: A theory for archicortex. Philos. Trans. R. Soc. Lond. B Biol. Sci. 262: 23-81.
McClelland, J.L., McNaughton, B.L., and O'Reilly, R.C. 1995. Why there are complimentary learning systems in the hippocampus and neocortex: Insights from the successes and failures of connectionist models of learning and memory. Psychol. Rev. 102: 419-457.

McEchron, M.D., Bouwmeester, H., Tseng, W., Weiss, C., and Disterhoft, J.F. 1998. Hippocampectomy disrupts auditory trace fear conditioning and contextual fear conditioning in the rat. Hippocampus 8: 638-646.

McGaugh, J.L. 2000. Memory-A century of consolidation. Science 287: 248-251.

Paxinos, G. and Watson, C. 1997. The rat brain in stereotaxic coordinates. Academic Press, San Diego.

Quinn, J.J., Oommen, S.S., Morrison, G.E., and Fanselow, M.S. 2002. Post-training excitotoxic lesions of the dorsal hippocampus attenuate forward trace, backward trace, and delay fear conditioning in a temporally-specific manner. Hippocampus 12: 495-504.

Quinn, J.J., Loya, F., Ma, Q.D., and Fanselow, M.S. 2005. Dorsal hippocampus NMDA receptors differentially mediate trace and contextual fear conditioning. Hippocampus 15: 665-674.

Ribot, T.A. 1882. Diseases of memory. Appleton-Century-Crofts, New York.

Scoville, W.B. and Milner, B. 1957. Loss of recent memory after bilateral hippocampal lesions. J. Neurochem. 20: 11-21.

Siapas, A.G. and Wilson, M.A. 1998. Coordinated interactions between hippocampal ripples and cortical spindles during slow-wave sleep. Neuron 21: 1123-1128.

Siapas, A.G., Lubenov, E.V., and Wilson, M.A. 2005. Prefrontal phase locking to hippocampal theta oscillations. Neuron 46: 141-151.

Simon, B., Knuckley, B., Churchwell, J., and Powell, D.A. 2005. Post-training lesions of the medial prefrontal cortex interfere with subsequent performance of trace eyeblink conditioning. J. Neurosci. 25: 10740-10746.

Squire, L.R. 1992. Memory and the hippocampus: A synthesis from findings with rats, monkeys, and humans. Psychol. Rev. 99: 195-231.

Squire, L.R. and Alvarez, P. 1995. Retrograde amnesia and memory consolidation: A neurobiological perspective. Curr. Opin. Neurobiol. 5: $169-177$.

Squire, L.R., Stark, C.E., and Clark, R.E. 2004. The medial temporal lobe. Annu. Rev. Neurosci. 27: 279-306.

Sutherland, G.R. and McNaughton, B. 2000. Memory trace reactivation in hippocampal and neocortical neuronal ensembles. Curr. Opin. Neurobiol. 10: 180-186.

Takehara, K., Kawahara, S., Takatsuki, K., and Kirino, Y. 2002. Time-limited role of the hippocampus in the memory for trace eyeblink conditioning in mice. Brain Res. 951: 183-190.

Takehara, K., Kawahara, S., and Kirino, Y. 2003. Time-dependent reorganization of the brain components underlying memory retention in trace eyeblink conditioning. J. Neurosci. 23: 9897-9905.

Takehara-Nishiuchi, K., Kawahara, S., and Kirino, Y. 2005. NMDA receptor-dependent processes in the medial prefrontal cortex are important for acquisition and the early stage of consolidation during trace, but not delay eyeblink conditioning. Learn. Mem. 12: 606-614.

Takehara-Nishiuchi, K., Nakao, K., Kawahara, S., Matsuki, N., and Kirino, Y. 2006. Systems consolidation requires postlearning activation of NMDA receptors in the medial prefrontal cortex in trace eyeblink conditioning. J. Neurosci. 26: 5049-5058.

Teyler, T.J. and DiScenna, P. 1986. The hippocampal memory indexing theory. Behav. Neurosci. 100: 147-154.

Wiltgen, B.J. and Silva, A.J. 2007. Memory for context becomes less specific with time. Learn. Mem. 14: 313-317.

Wiltgen, B.J., Brown, R.A.M., Talton, L.E., and Silva, A.J. 2005a. New circuits for old memories: The role of the neocortex in consolidation. Neuron 44: 101-108.

Wiltgen, B.J., Sanders, M.J., Ferguson, C., Homanics, G.E., and Fanselow, M.S. 2005b. Trace fear conditioning is enhanced in mice lacking the $\delta$ subunit of the GABAA receptor. Learn. Mem. 12: 327-333.

Zola-Morgan, S.M. and Squire, L.R. 1990. The primate hippocampal formation: Evidence for a time-limited role in memory storage. Science 250: 288-290.

Received October 21, 2007; accepted in revised form March 17, 2008. 


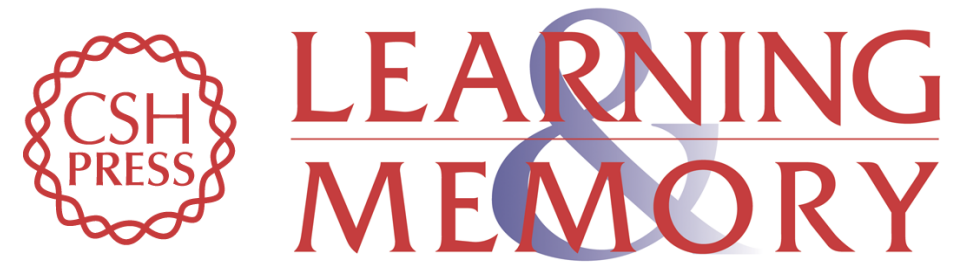

\section{Inverse temporal contributions of the dorsal hippocampus and medial prefrontal cortex to the expression of long-term fear memories}

Jennifer J. Quinn, Quang D. Ma, Matthew R. Tinsley, et al.

Learn. Mem. 2008, 15:

Access the most recent version at doi:10.1101//m.813608

References This article cites 38 articles, 12 of which can be accessed free at: http://learnmem.cshlp.org/content/15/5/368.full.html\#ref-list-1

License

Email Alerting

Receive free email alerts when new articles cite this article - sign up in the box at the Service top right corner of the article or click here. 